\title{
The social impacts of stormwater management techniques
}

\author{
S. Apostolaki. ${ }^{1}$, C. Jefferies ${ }^{1 *}$ and T. Wild ${ }^{2}$ \\ ${ }^{1}$ Urban Water Technology Centre, University of Abertay, Bell Street, Dundee,DD1 1HG, UK \\ ${ }^{2}$ Scotland and Northern Ireland Forum for Environmental Research (SNIFFER), Edinburgh \\ Greenside House, 25 Greenside Place, Edinburgh EH1 3AA \\ *Corresponding author, e-mail c.jefferies@abertay.ac.uk
}

\begin{abstract}
This paper presents the results of research into the social impacts of stormwater management techniques applied within urban environments. The main aim of the study was to compare public and professional attitudes of stormwater management practices such as Sustainable Urban Drainage Systems (SUDS) and river management techniques.

Any new and innovative technology used in residential areas, besides being economically and environmentally acceptable, must also be accepted by the residents. There has been considerable interest in the assessment of the public perception of SUDS in the UK by consultants, developers, the Environment Agency of England and Wales as well as by the Scottish Environment Protection Agency (SEPA). This research was undertaken to inform such interest and also to obtain a more holistic view of the perception by professionals of SUDS. A comparative study of the perceptions of river management in three densely populated European cities facing similar storm water management problems was carried out. The selected cities were Glasgow in Scotland - U. K., an area in west London, England U.K., and part of Athens - Greece. All sites were located within flood-prone suburban areas, and different river management techniques have been proposed or adopted.
\end{abstract}

\section{KEYWORDS}

Public perception; stormwater pollution; sources; SUDS

\section{INTRODUCTION}

Water is one of the most important elements of the landscape and a common characteristic of any human society is that communities tend to settle near water (Appleton, 1975). Litton (1977) referred to visual assessment of river landscapes: "Water in the landscape tends to be dominant because of its visibility, its movement, reflections, and colour, its consequent contrasts to adjacent earth surfaces." However, the acceptability and perception of the visual qualities of water is influenced by many parameters that are worth examining. Most residents of cities consider open watercourses as being risky for children and pets. However, aesthetics seem to influence public attitudes even when matters such as safety are involved. For the majority of the public, the more aesthetically pleasing (i.e natural looking), an urban watercourse is, the safer it is perceived to be. The physical distance from the watercourse also seems to play important role in formulating attitudes towards the water body, as indicated by previous work of the author (Apostolaki et al, 2003). Residents with direct access to watercourses focus on the water quality and safety of systems while those living further away are more concerned with the visual characteristics of the landscape. 
Sustainable stormwater management techniques, as a component part of sustainable construction, are gaining ground within new planning concepts. However, their acceptability by stakeholders and the public is still debatable and depends on many parameters such as technical details of the schemes in terms of function, efficiency \& maintenance, ecological \& biological factors, and the economic factors of amenity issues \& social concerns. The social impacts of new stormwater management schemes and technologies, although of major importance within urban environments, have been often ignored. Stormwater management is becoming increasingly important in urban areas due to increasingly frequent flood incidences in big cities with the consequent need for the collection and treatment of runoff. The management of flows in small rivers, in combination with the application of Sustainable Urban Drainage Systems are thought by many to provide appropriate solutions for heavily urbanised areas.

A simple way of describing SUDS, in accordance with the sustainable development "threering circus model" (Butler, 2002) which actually is the representation of the intersection between the social, environmental, and economic goals of sustainable development, is also the use of the same model encompassing the target activity areas of sustainable urban drainage (CIRIA, 2000).

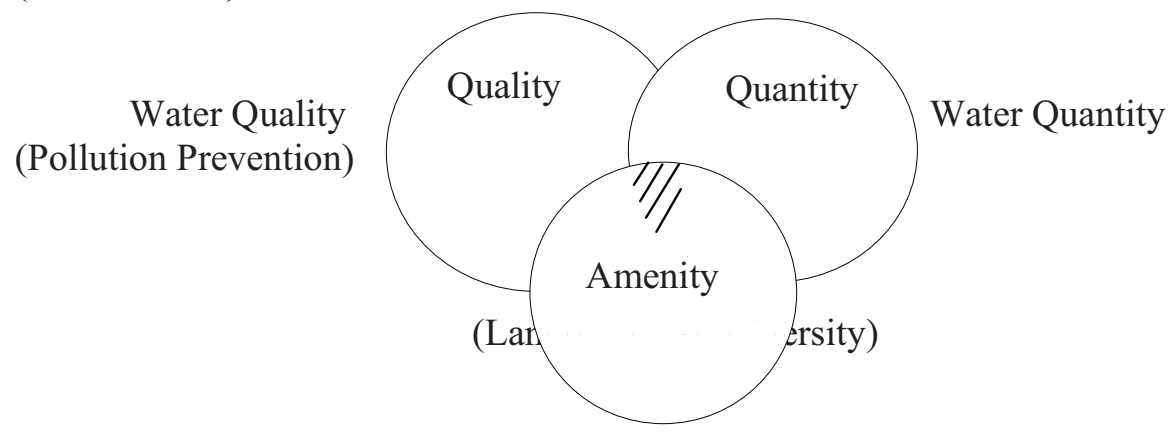

Figure 1. SUDS three-ring circus model.

The public's perception of environmentally friendly constructions and practices is influenced by a range of factors including the schemes' characteristics such as aesthetics, appearance and surroundings, by the biological/ecological performance, attenuation (flood abatement) and water quality. Other issues to be considered when open watercourses are located within residential include safety, amenity, biodiversity and concepts such as urban restoration and best "space management".

During this research programme (SNIFFER, 2005), several surveys on the assessment of public and professional perceptions of stormwater management practices were carried out and they all showed that the level of public awareness and the information provided to householders play a very important role in formulating public opinion on stormwater management practices and in generating positive thinking.

\section{METHODOLOGY}

The purpose of this research was to assess the social impacts of different stormwater management practices. A combination of investigative methods was chosen, each of the three research stages serving a different objective:

- Assessment of public awareness and perception of SUDS (mainly ponds) in the U.K.;

- Assessment of professional perception of SUDS in the U.K.; 
- Evaluation and comparison of different stormwater management techniques, from a social perspective, in areas of three large European cities.

The nature of the project forced the use of a combination of quantitative and qualitative methods. During the first stage, the public perception of SUDS in the U.K. was assessed by quantitative methods which made use of experience gained during previous research on the public perception of SUDS in Scotland (Apostolaki et al., 2001). The second stage, which involved the assessment of the professional perception of SUDS in the U.K., made use of qualitative methods, semi-structured interviews and focus groups. Finally, the third stage used a combination of research methods to assess public and professional perception of river management techniques in areas of Glasgow, London, and Athens, based on the experience gained through the previous research phases. The different approaches are presented in Table 1 .

Table 1. Research phases and Methodological approaches

\begin{tabular}{|c|c|c|}
\hline RESEARCH PHASES & PERIOD & METHODOLOGIES \\
\hline 1. Public Perception of SUDS in the U.K. & $\begin{array}{l}2001 \\
2002\end{array}$ & $\begin{array}{l}\text { Quantitative Research } \\
\text { Door-to-door interviewer-administered } \\
\text { questionnaires with open-ended questions } \\
\text { addressed to the public }\end{array}$ \\
\hline $\begin{array}{l}\text { 2. Professional Perception of SUDS in the } \\
\text { U.K. }\end{array}$ & $\begin{array}{l}2002 \\
2003 \\
\end{array}$ & $\begin{array}{l}\text { Qualitative Research } \\
\text { Semi-structured interviews applied to } \\
\text { professionals }\end{array}$ \\
\hline $\begin{array}{l}\text { 3. Public \& Professional Perception of } \\
\text { Stormwater Management Techniques in } \\
\text { U.K. \& Greece }\end{array}$ & $\begin{array}{l}2003 \\
2004 \\
\end{array}$ & $\begin{array}{l}\text { Combination of Quantitative \& Qualitative } \\
\text { Methods }\end{array}$ \\
\hline $\begin{array}{l}\text { a. Public Perception of a stormwater } \\
\text { management scheme in Glasgow, U.K. }\end{array}$ & & $\begin{array}{l}\text { Quantitative Methods -Door-to-door } \\
\text { interviewer-administered questionnaires with }\end{array}$ \\
\hline $\begin{array}{l}\text { b. Public Perception of a stormwater } \\
\text { management scheme in London, U.K. }\end{array}$ & & t \\
\hline $\begin{array}{l}\text { c. Public and Professional Perception of a } \\
\text { stormwater management scheme in } \\
\text { Athens, Greece. }\end{array}$ & & $\begin{array}{l}\text { Qualitative Methods - Semi-structured } \\
\text { interviews applied to members of the public and } \\
\text { professionals }\end{array}$ \\
\hline
\end{tabular}

The Sphinx Questionnaire software package was used for the design of the questionnaires, the data input, and for the quantitative analysis of results, in all research phases.

\section{RESULTS}

The results are of interest to a range of stakeholders, such as policy makers, water utilities, local authorities, planners, developers, consultancies active in urban construction, and researchers. The recommendations on public and professional attitudes can be utilised to improve newly applied stormwater management systems in matters of public acceptability. This knowledge can help stakeholders make improvements to SUDS and other stormwater management practices, and in this way enhance public acceptability.

\section{$1^{\text {ST }}$ Research phase - Public perception of SUDS in the U.K.}

Although the trend of using SUDS in residential areas was increasing at the time this work was commissioned, very little research had been conducted to assess the various attitudes 
towards the systems, or to assess the perception of issues directly involving SUDS such as amenity, landscape, restoration and biodiversity. One study investigating stakeholder attitudes was undertaken in 1998 in Scotland, England, and Wales (McKissock et. al., 1999). Another study investigated the public perception of SUDS in Dundee and Dunfermline (Apostolaki et. al., 2001). One of the main outcomes of both surveys was that the level of public awareness and the information provided to householders both play a very important role in formulating public opinion on SUDS, and in generating positive thinking towards the systems. Similar surveys in the U.S.A. (Feature Article, 2000), and Sweden (Hjerpe \& Krantz, 2000) came to similar conclusions. A recent study undertaken by Hyder Consulting on behalf of SEPA assessed stakeholders' perceptions of SUDS and evaluated the use of guidance on SUDS in Scotland. The conclusions were that the level of awareness strongly influences views on the amenity, biodiversity and safety advantages of SUDS (Wild et al., 2003).

Social perception surveys were applied in several areas with ponds in England in spring 2002, specifically in Lancashire, on the South Coast, and in Gloucestershire. It was concluded that the improvement of the aesthetics of the area, the attraction of wildlife, and the creation of a new habitat were the principal perceived advantages. The increase in amenity and the avoidance of flooding, were included as advantages. However, the perceived advantages differed according to the site characteristics. The aesthetics of a scheme most influences public attitudes. The results from the 2002 survey are summarised in Figure 2.

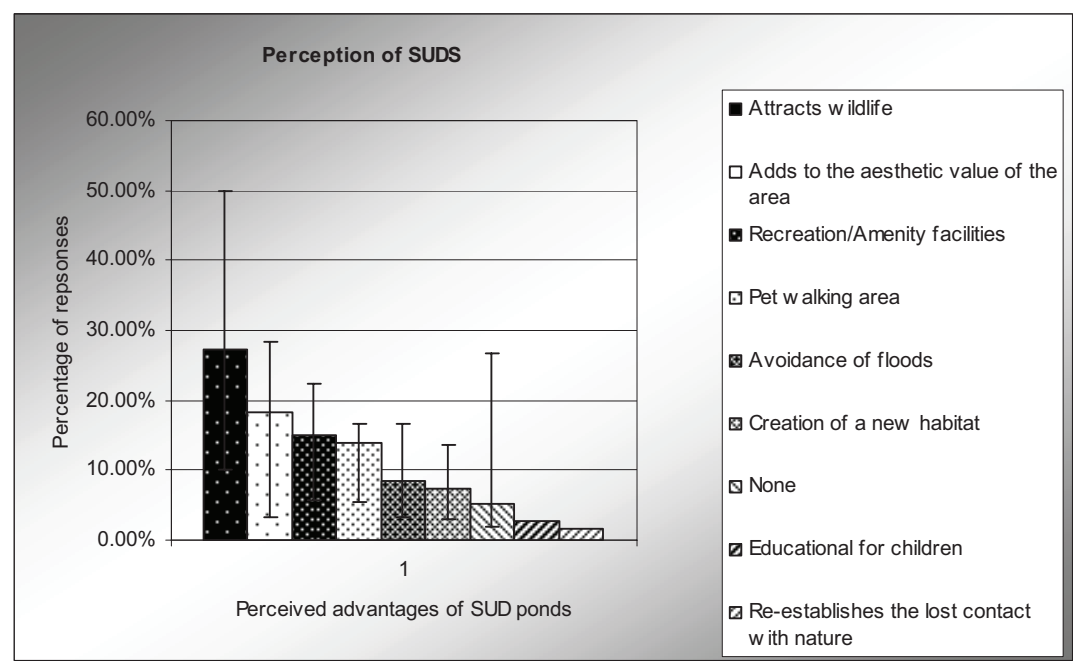

Figure 2: Overall advantages of ponds (public perception survey, 2002)

The main concern expressed was over safety and specifically over the potential danger of children drowning in the ponds. Again the results were site specific and highly dependent on the aesthetics of the scheme and its amenity value in the area. In areas of high aesthetic value with rich marginal vegetation, safety barely appeared as a concern, while in areas with less attractive ponds, safety concerns were expressed by up to $70 \%$ of the participants. Poor maintenance of ponds, and litter pollution were also regarded as disadvantages.

Although safety was the major concern of the public, the vast majority of those expressing such worries $(80 \%$ on average) still preferred to live close to the schemes. By comparison, living close to a SUD pond was considered to be less dangerous than living close to heavy road traffic or to a river, but slightly more dangerous than living close to a natural pond. This again points to the pond being more likely to be acceptable, the more natural it appears. 
$2^{\text {nd }}$ Research phase - Professional perception of SUDS in the U.K.

A range of interesting views were expressed by professionals involved in SUDS, and the results of the Focus Groups are in complete accordance with those of the interviews. In terms of amenity, SUDS were considered to be of high value when constructed and maintained according to the design requirements and to look as natural as possible. According to the professionals the term amenity includes ideas such as visual and habitat enhancement; wildlife and biodiversity benefits; the provision of an urban park environment for recreation, relaxation, and leisure; stress relieving area; educational benefits; and area of high aesthetic value. If SUDS are designed with amenity in mind they become part of the local landscape and the participants believed that SUDS have the potential to be beneficial to biodiversity, since they create new habitats within urban areas.

Although the potential risk related to the SUD ponds and wetlands was recognised, professionals believed that the actual risk is extremely low or insignificant. Provided that SUDS schemes are designed with safety in mind, and a proper drainage impact assessment has taken into account the flooding risk from rising groundwater, safe schemes may be located within urban areas.

Many barriers to SUDS application were outlined, the most commonly mentioned being adoption and maintenance, the land take, the lack of knowledge amongst specialists, and the water authority's hesitation in accepting the systems as indicated in figure 3.

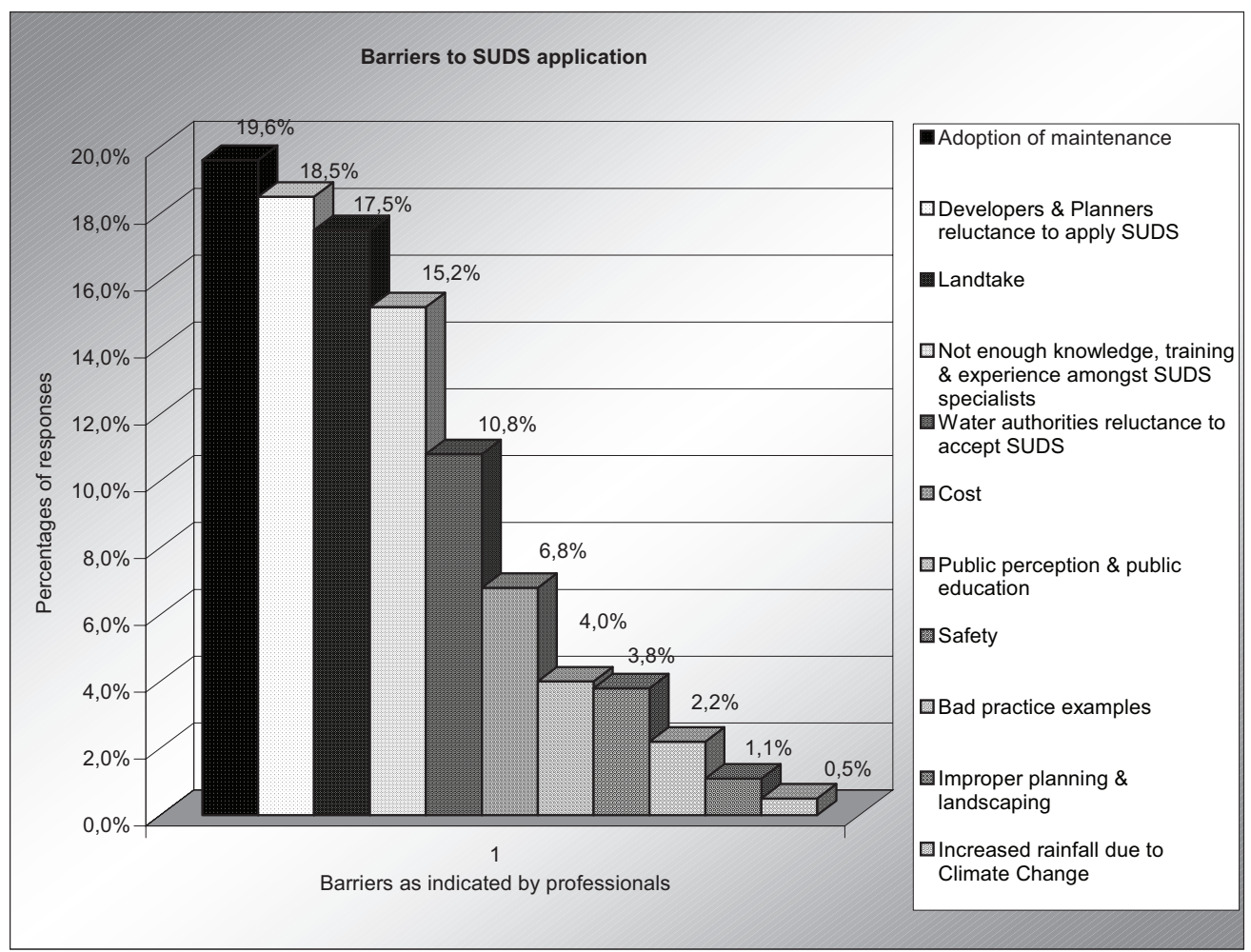

Figure 3: Barriers to SUDS application 


\section{$3^{\text {rd }}$ Research phase - Comparative study of river management techniques engaged in the U.K and Greece.}

Evaluation of river engineering practices from a social perspective has resulted in a more holistic view of the social impacts of stormwater and river management techniques applied in large cities on an international level. Given the fact that the engineering solutions adopted in the three areas were completely different even though all three areas face similar problems, the results do provide a good basis for comparison. All the study areas were of similar socioeconomic backgrounds, and in all areas there was a wide diversity of cultural backgrounds, as they form parts of multinational societies, especially in the cases of London and Athens.

Glasgow Overall, the majority of the participants agreed with the proposed plans for Glasgow, which involved a combination of river restoration techniques and SUDS. As expected the major public concern was over safety. However, this was not as high as to put off the residents from approving the suggested plans. Flooding was identified as the second main concern. As a result, the participants were in favour of suggestions that could reduce the risk of flooding and could also provide amenity and recreational facilities. The idea of bringing the local stream back to its natural form was welcomed by most of the participants. The advantages of the suggested plan as seen by the participants in the survey are shown in Figure 4. The participants believe there is a need for redevelopment of the area to improve aesthetics and make it safer, as crime is another major concern in the Tollcross and Sandyhills area.

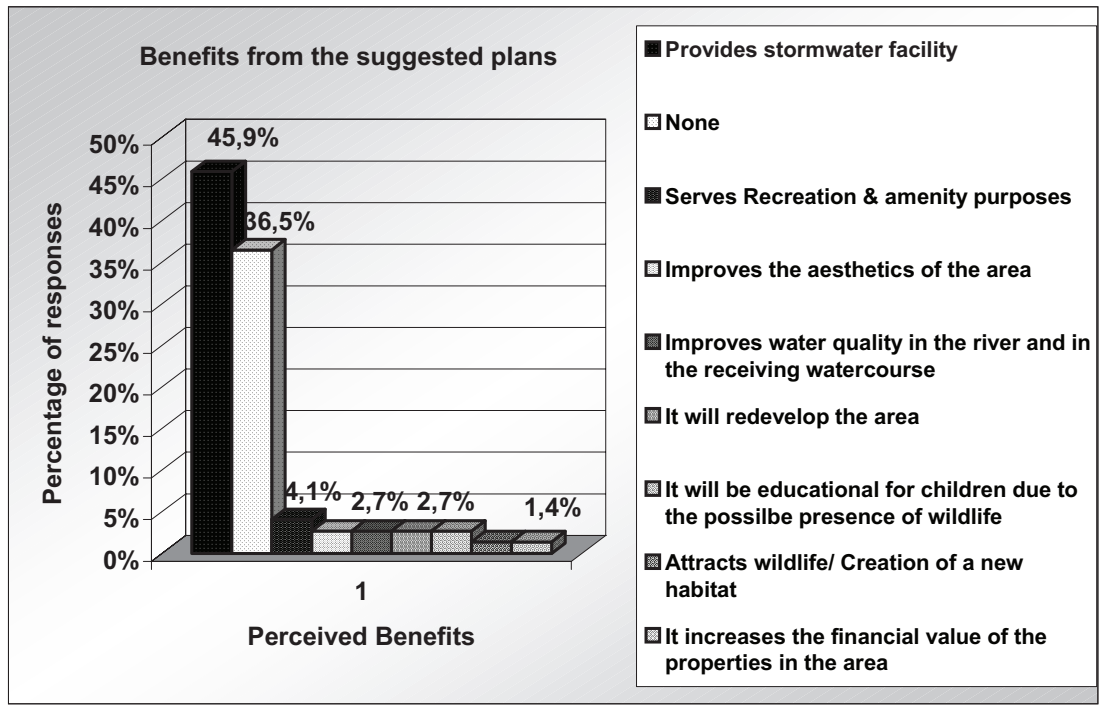

Figure 4: Perceived advantages of the suggested Stormwater management plan for Glasgow

London The residents of the London study area were positive towards the river restoration scheme that has already taken place in their area. A small number of participants believed that the re-opening of the river was a waste of money, and they showed preference towards traditional ways of treating runoff and the practice of culverting the rivers running through residential areas. Those attitudes were mainly driven from the residents' high concern over safety. All public suggestions are shown in Figure 5: 


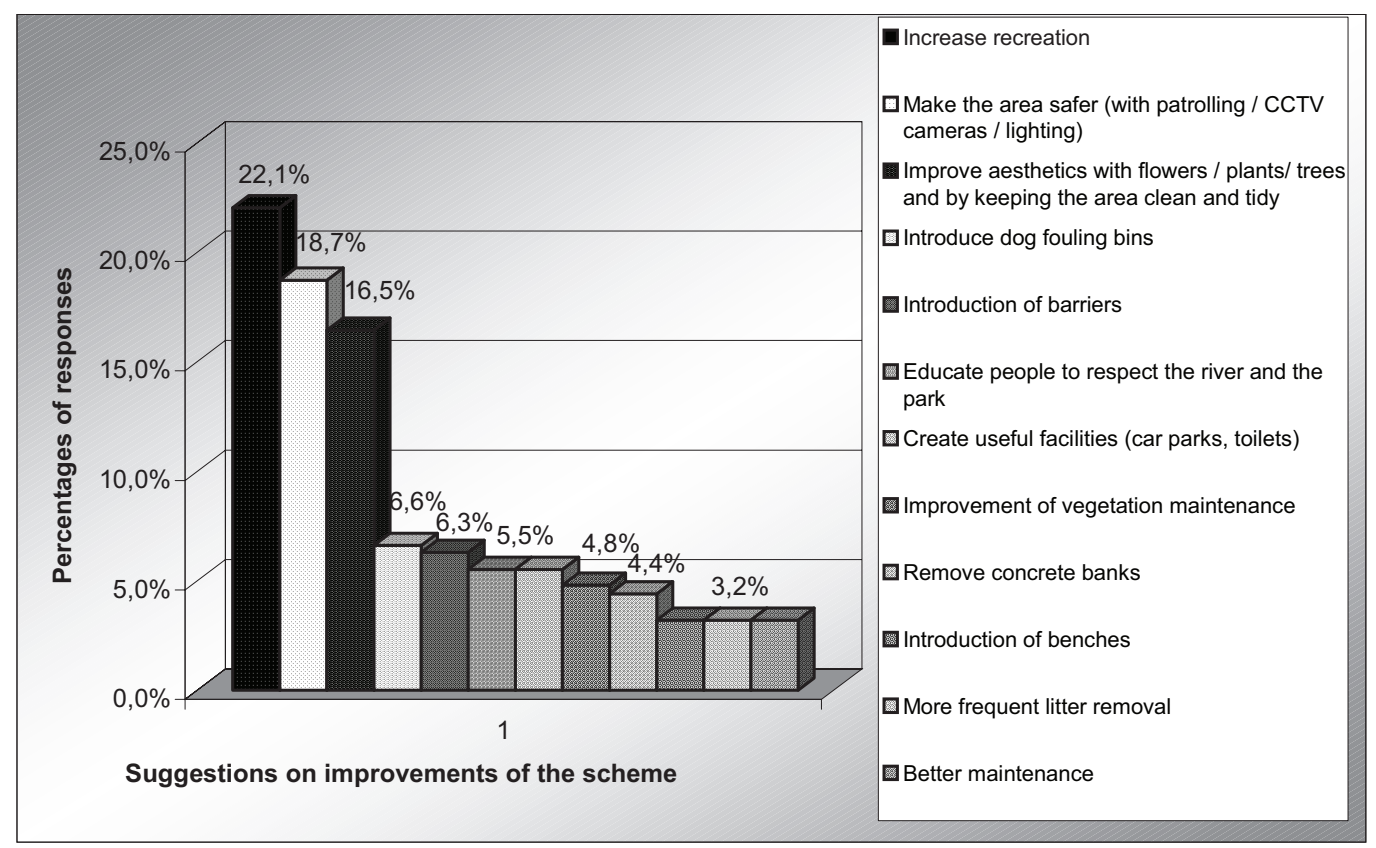

Figure 5: Suggestions to improve appearance of Tokyngton Park, London

Athens In this study, views were sought of a major project culverting the Kifisos river, the biggest river of the Attica region. The solution adopted, and the construction of a motorway over it, was highly undesirable. The decision was characterised as "anachronistic", inefficient, and environmentally unfriendly. The public also disapproved of the works at Kifisos, believing that their wellbeing was not taken into consideration when the plan was selected. However, to the decision makers, this solution was seen as a way to "kill two birds with one stone", which in this case meant to solve the flooding problem of the southern suburbs of Athens and at the same time to provide a solution for the traffic problem of the city. However, the participants in the survey believe this scheme fails to meet both requirements.

Safety did not appear to be an important issue at Kifisos. As the participants stated, although safety is usually a matter of concern when it comes to open channels running through cities, safety was never an issue at Kifisos, except of times of severe flooding events. In general the participants believed that the safety concern is mainly a matter of education of the public rather than an actual risk. In general the participants in all three surveys clearly stated their preference towards more natural systems and sustainable management of rivers, and they expressed the hope that the solution adopted at Kifisos can be seen as a negative example that should be avoided by any means in the future.

\section{CONCLUSIONS}

In contrast to surveys of public attitudes towards catchment pollution applied in the U.S., most people in the U.K. (92\%) were able to link their everyday activities to potential catchment pollution. Amongst the most important perceived advantage of open watercourses is the fact that they help to re-establish the relationship between urban citizens and nature. Several respondents, members of the public and professionals, believed that the open 
$10^{\text {th }}$ International Conference on Urban Drainage, Copenhagen/Denmark, 21-26 August 2005

watercourses have been successful in creating a natural feature within the urban environment and in reminding urban citizens of their lost links with nature.

However, attitudes differ according to site characteristics, and are strongly influenced by the aesthetics and the amenity benefits of the schemes. In areas with well-established schemes, the participants tended to be more positive. In these areas the perceived advantages outweighed the disadvantages. However, maintenance and cleaning up of the scheme and its surroundings was a major issue indicating the public preference for a clean, tidy and attractive urban environment.

Overall, the public in both countries examined, U.K. and Greece, prefers the engagement of sustainable practices in rivers. Natural landscaping, improvement of aesthetics, as well as environmental and societal benefits of new schemes seem to become increasingly important for urban citizens. Finally, public consultation prior to the construction of stormwater management schemes is vital, especially for large projects in residential areas.

\section{ACKNOWLEDGEMENTS}

The authors acknowledge the Environment Agency, and HR Wallingford Ltd. for funding the research. Additionally, the authors would like to thank SEPA and Sniffer for support. Special thanks go to Alison Duffy and Fiona Napier for their assistance with the surveys in the U.K.

\section{REFERENCES}

Apostolaki S., Jefferies C., Smith M. \& Chatfield P., 2003, "Perception and social acceptability of sustainable urban drainage systems", First International Conference on "Sustainable Development and Management of the Subsurface", Utrecht, Netherlands, November.

Apostolaki S., Jefferies C., Souter N. 2001, Assessing the public perception of SUDS at two locations in Eastern Scotland, First National Conference on SUDS, Coventry University.

Appleton, I., "The experience of landscape". Iohn Wiley \& Sons, New York, 1975

CIRIA 2000 Sustainable Urban Drainage Systems; Design Manual for Scotland \& Northern Ireland. Report No. 621. Construction Industry Research and Information Association, Storey's Gate London.

Butler D., 2002, "Sustainable Development and the water industry", Presentation given at SWARD Launch Queen Anne's Gate, London, $4^{\text {th }}$ March.

Feature Article, 2000, “On Watershed Education”, Journal on Watershed Protection Techniques, Vol. 3, No 3, March.

Hjerpe M. \& Krantz H., 2000, "Handling stormwater in open structures: a case study of critical factors for sustainability”, Department for Water and Environmental Studies, Linkoping University of Sweden, presented at the IWA conference in Berlin.

Litton Jr., R.B., "River landscape quality and its assessment". In: Proceedings of the Symposium on River Recreation Management and Research, Gen. Tech. Rep. NC-28, Northcentral For. Exp. Stn. US Department of Agriculture, St. Paul, MN., 1977

McKissock G, Jefferies C \& D'Arcy B, 1999, An assessment of drainage best management practices in Scotland. J.C.I.W.E.M. 13 No. 1 pp 47-54. February.

SNIFFER, 2005 Social Impacts of Stormwater Management Techniques Including River Management and SUDS. Report No. SUDS01 Scotland and Northern Ireland Forum for Environmental Research, Edinburgh, February.

Wild T.C., McKissock G.,D’Arcy B. J., Shaffer P., Elliott C., 2003, “An Evaulation of SUDS guidance in Scotland", Proc. Second National Conference on Sustainable Drainage Coventry University, 23-24 June 2003 